\title{
A new Clinical Effectiveness Unit for the Faculty of Family Planning and Reproductive Health Care
}

\author{
Gillian Penney, FRCOG, MFFP, Honorary Director, Clinical Effectiveness Unit, Faculty of Family Planning and Reproductive \\ Health Care, London, UK
}

Correspondence: Gillian Penney, Aberdeen Maternity Hospital, Cornhill Road, Aberdeen AB25 2ZD, UK. Tel +44 (0) 1224552614. E-mail: g.c.penney@abdn.ac.uk

(Accepted 14 ${ }^{\text {th }}$ August 2002)

The Journal of Family Planning and Reproductive Health Care 2002: 28(4): 175-176

\section{Background}

Among the stated aims of the Faculty of Family Planning and Reproductive Health Care (FFPRHC) are commitments to provide information in support of basic and continuing education in the discipline, and to encourage audit. These aims are addressed primarily through the work of one of the Faculty's eight standing committees, the Clinical Effectiveness Committee (CEC).

The remit of this Committee includes researching and answering enquiries from the membership; preparing guidelines for clinical practice; advising members on audit, and advising the Faculty Council on new and emerging issues in the field of family planning and reproductive health care. Since 1998, the work of the CEC has been supported by a small Clinical Effectiveness Unit (CEU) based within the Faculty offices in London.

During 2001, Faculty Council felt that the work of the Unit might benefit from being based within a host academic or clinical unit and sought bids from individuals wishing to serve as Honorary Director of the new Unit, and to accommodate it within their own base department.

In March of this year, a bid from the University of Aberdeen was accepted by the Faculty and I was appointed as Honorary Director of the new CEU. Our team in Aberdeen is delighted to have been awarded the contract to run the Faculty CEU for the next 3 years and look forward to serving Faculty members in a range of ways. The work of the CEU will be closely linked with that of the Scottish Programme for Clinical Effectiveness in Reproductive Health (SPCERH), of which I am the National Coordinator. Our bid to the Faculty was very much a joint initiative with my colleagues Dr Gillian Flett, Director of Sexual and Reproductive Health Services for Grampian, and Professor Allan Templeton, Head of the Academic Department of Obstetrics and Gynaecology. These colleagues will be actively involved in the work of the Unit and in the supervision of its staff, ensuring that both community and academic perspectives are provided.

\section{Unit staff}

Funding from the FFPRHC, with additional support from the University of Aberdeen, will allow the appointment of a full-time research assistant (with a Masters degree in a relevant biomedical science), a senior secretary and a clinical senior lecturer. The latter will devote half her time to the work of the $\mathrm{CEU}$, in the capacity of unit co-ordinator, while devoting her remaining time to clinical work in the discipline. This arrangement will ensure that the Unit is kept very aware of grass-roots clinical issues.

\section{Unit workplan}

During its first year it is proposed that the CEU will undertake the tasks detailed in the following paragraphs.

\section{Clinical enquiry service}

From September 2002, the CEU will take over the role of receiving clinical enquiries from Faculty members. Mechanisms will be established so that enquiries can be submitted by letter, e-mail, fax or telephone. Members' individual enquiries will be reworded as 'generalisable clinical questions' by Unit staff. Unless an enquiry closely mirrors one received previously, and an answer is available 'off the peg', a literature search will be undertaken by Unit staff. A standardised response format will be developed, making explicit the extent of literature review undertaken and the conclusions reached. We aim to respond to enquirers within 48 hours, unless complex queries require wider consultation.

All generalisable clinical questions and responses will be posted on the Faculty website for the information of other members. In addition, on an annual basis, enquiries will be collated and a list of frequently asked questions (FAQs) compiled. These annual summaries and updated responses will be published in the Journal of Family Planning and Reproductive Health Care (JFPRHC).

\section{FFPRHC Guidance}

Historically, the Faculty has published a range of 'guidance products' for members: FACT reviews, recommendations for clinical practice and short scientific reviews. Some have been authored by Faculty staff and some by invited members. These publications have held differing status, and it has been unclear which represented the 'official' view of the Faculty. For simplicity and clarity, the new CEU will develop only one type of guidance product: FFPRHC Guidance. The Unit will develop four to six such documents annually. Some will address new topics, and some will constitute revisions of old-style Faculty guidance products. Four topics have been selected by the CEC for the Unit's Year 1 workplan. These comprise two new topics (Intrauterine Devices for Long-term Contraception and Hormonal Contraception and Inflammatory Bowel Disease) and two revisions (Emergency Contraception and First Prescription of the Oral Contraceptive Pill).

FFPRHC Guidance publications will be developed in a standard way which, we hope, will combine scientific rigour with reasonable expediency. I will draw on my past experience of guideline development, obtained through involvement with both the National Institute for Clinical Excellence (NICE) and the Scottish Intercollegiate 
Guideline Network (SIGN), in developing our methods. Guidance development will follow a stepwise approach involving: framing of clinical questions; literature search, critical appraisal and summary in evidence tables; considered judgement of evidence to form graded recommendations; and peer review. We will no longer be inviting Faculty members to author guidance products, but will involve a wide range of members at the 'considered judgement' and 'peer review' stages.

FFPRHC Guidance reports will be published within the JFPRHC and on the Faculty website. Each Guidance report will be forwarded to the Faculty Education Committee, which will take responsibility for the development of related self-assessment test questions. The valuable educational role of the FACT series will therefore be retained.

\section{New Product Reviews}

The CEU will maintain a watching brief for new family planning products scheduled to be launched within the UK. The CEU will liaise with pharmaceutical companies and review the international literature in order to provide Faculty members with brief New Product Reviews prior to the UK product launch. The first such review, scheduled for early autumn, will relate to Cerazette, a desogestrel-only contraceptive pill (Organon). New Product Reviews will be published on the Faculty website, and publicised in Faculty News.
Implementation and monitoring

We recognise that clinical effectiveness involves not only developing clinical guidance but also taking active steps to implement that guidance and to monitor its impact on clinical practice. The CEU will therefore have both implementation and audit roles. All Guidance reports will be disseminated by both paper and electronic publication. The linked self-assessment tests to be developed by the Education Committee will promote implementation. In addition, we propose to develop specific implementation strategies for selected Guidance reports, tailored to overcome identified barriers to their adoption. Such strategies are likely to include provision of structured clinical records or care pathways for specific clinical problems, and support for local action planning.

The Unit will also undertake short-term audit exercises to monitor the uptake of selected Guidance reports. Audit tools to be used will include surveys of Faculty members and of service users and case note review.

Initially, enquiries for the CEU should be addressed to the Honorary Director at the address given at the top of this article. Contact details for Unit staff will be published on the Faculty website as soon as possible.

Statements on funding and competing interests

Funding. None identified.

Competing interests. None identified.

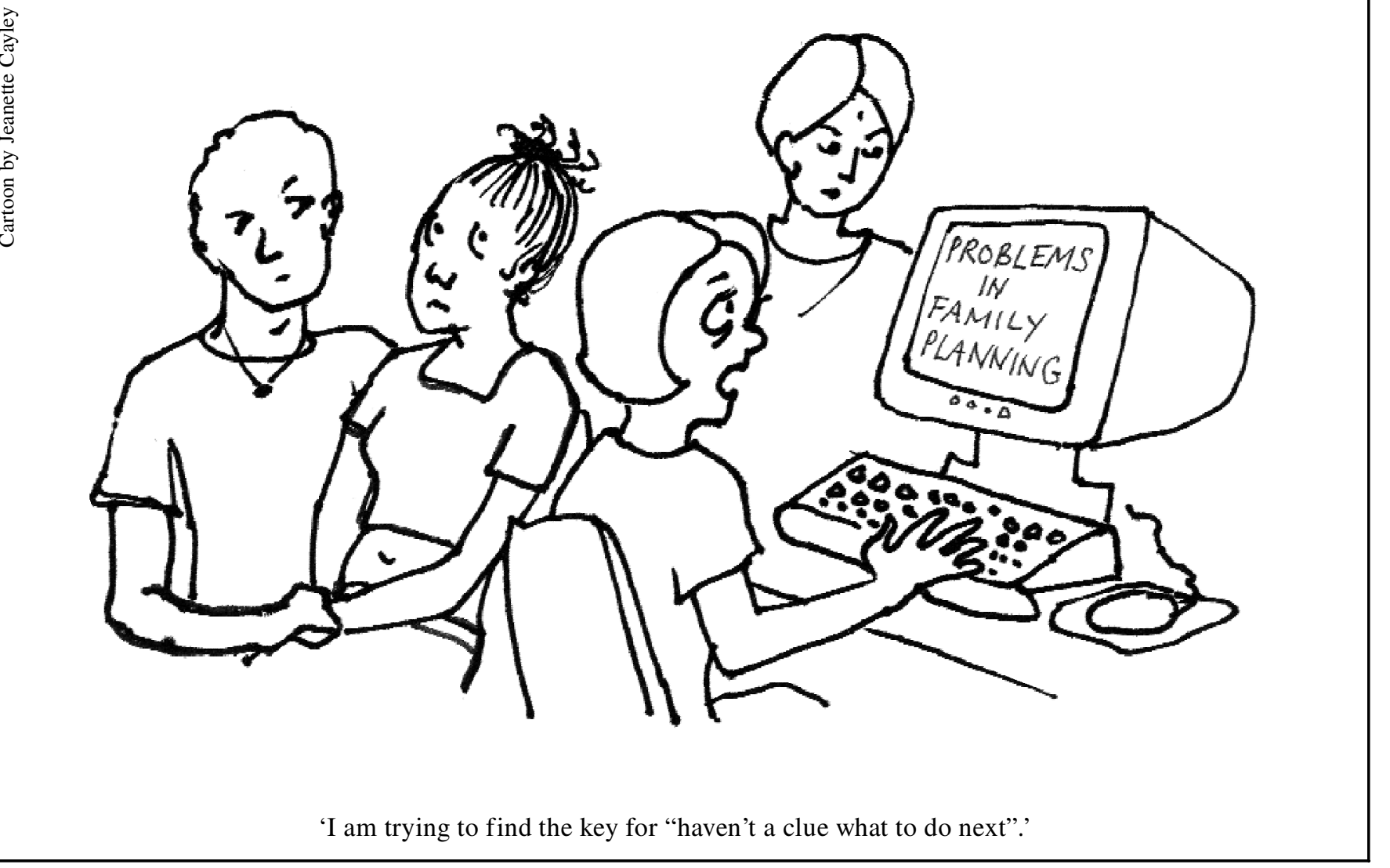

